\title{
Construction and validation of a scale of assessment of self-care behaviours anticipatory to creation of arteriovenous fistula
}

\author{
Clemente Neves Sousa, Maria Henriqueta Figueiredo, Vanessa Filipa Dias, Paulo Teles and \\ João Luís Apóstolo
}

Aims and objectives. We developed a scale to assess the self-care behaviours developed by patients with end-stage renal disease to preserve the vascular network prior to construction of arteriovenous fistula.

Background. The possibility of creation of an arteriovenous fistula depends on the existence of an arterial and venous network in good condition, namely the size and elasticity of the vessels. It is essential to teach the person to develop self-care behaviours for the preservation of the vascular network, regardless of the modality of dialysis selected. Design. Methodological study.

Methods. The scale was developed based on clinical experience and research conducted by the researcher in the area of the vascular access for haemodialysis. The content of the scale was judged by two panels of experts for content validity. The revised version of the scale was administered to a convenience sample of 90 patients with end-stage renal disease. In the statistical analysis, we used the Cronbach's alpha, the Kaiser-Meyer-Olkin and scree plot and the principal component analysis with varimax rotation.

Results. A principal component analysis confirmed the univariate structure of the scale $\quad\left(\mathrm{KMO}=0.759, \quad\right.$ Bartlett's sphericity test-approximate $\chi^{2}$ 142.201, $p<0.000)$. Cronbach's $\alpha$ is 0.831 , varying between $0.711-0.879$.

Conclusion. This scale revealed properties that allow its use to assess the patients self-care behaviours regarding the preservation of the vascular network.

Relevance to clinical practice. This scale can be used to evaluate educational programmes for the development of self-care behaviours in the preservation of vascular network. This scale can identify not only the patients that are able to take care of their vascular network but also the proportion of patients who are not able to do it, that need to be educated.

Key words: arteriovenous fistula, haemodialysis, scale, self-care, vascular access
What does this paper contribute to the wider global clinical community?

- This scale can be used to develop future educational programmes for the development of self-care behaviours to preserve the vascular network.

- This scale can identify the selfcare behaviours most accomplished by patients with endstage renal disease to preserve vascular network.

Accepted for publication: 4 July 2015

Authors: Clemente Neves Sousa, PhD, RN, Adjunct Professor, Escola Superior Enfermagem Porto (Nursing Scholl of Porto), Porto and Diaverum Portugal; Maria Henriqueta Figueiredo, PhD, RN, Coordinator Professor, Escola Superior Enfermagem Porto (Nursing Scholl of Porto); Vanessa Filipa Dias, PhD Student, MPH, RN, Institute of Health Sciences, Católica University, Porto and Unidade de Saúde Familiar St. André de Canidelo, Vila Nova de Gaia; Paulo Teles, PhD, Adjunct Professor, School of Economics and LIAAD-INESC Porto LA, Porto University, Porto; João Luís Apostolo, PhD, RN, Adjunct Professor, Escola Superior Enfermagem Coimbra, Coimbra, Portugal.

Correspondence: Clemente Neves Sousa, Adjunct Professor, Escola Superior Enfermagem Porto (Nursing Scholl of Porto), Rua Dr. António Bernardino de Almeida, 4200-072 Porto, Portugal. Telephone: +351225073500 .

E-mail: clementesousa@esenf.pt 


\section{Introduction}

In the last two decades of the 20th century, the prevalence of end-stage renal disease (ESRD) has increased considerably in the developed or developing countries, growing around $20-25 \%$ in the last decade (USRDS, 2009). It is estimated that in the USA in 2030, the number of new cases of ESRD will exceed 450,000, and the number of people receiving dialysis or having a kidney transplant will exceed the 2 million (Schoolwerth et al. 2006).

To conduct the haemodialysis treatment the person needs to have a functioning and durable vascular access. Despite the developments achieved at the level of heterologous materials, arteriovenous fistula (AVF) is considered by the scientific community as the vascular access of excellence for performing haemodialysis (Pisoni et al. 2002, Besarab \& Brouwer 2004, Schon et al. 2007). The AVF has less infection process, of thrombosis and better patency when compared with the arteriovenous graft or central venous catheter (SEN Guidelines 2005, NKF-K/DOQI 2006; Tordoir et al. 2007).

\section{Background}

The literature highlights the contributions that nurses provide identifying problems and/or complications that may compromise the vascular access (Young et al. 2002, Konner et al. 2003, Nguyen et al. 2003, Pile 2004), as well teaching the person with the vascular access (Dinwiddie 2003, Nguyen et al. 2003, Sousa 2012). Several Guidelines recommend and emphasise that the patient should be taught to take care of vascular access (SEN Guidelines 2005, NKF-K/DOQI 2006; Tordoir et al. 2007). However, there are few studies that assess the self-care behaviours with the AVF. Sousa et al. (2014) conducted a review of the literature that showed the need to develop a structure that organises and describes the interventions to be developed that enable people to develop self-care behaviours with the AVF. The same authors found a lack of tools for assessing self-care behaviours with the AVF. It is clearly important to develop tools to assess self-care behaviours with the AVF, regardless of the dialysis modality chosen by the person. Sousa et al. (2014) showed that the teachings can be divided into four moments, depending on the stage of ESRD: self-care prior to construction, postconstruction self-care, self-care during maturation and selfcare in haemodialysis. With respect to self-care behaviours associated with the time before construction, several authors value preserving the vascular network, in particular the venous network in the nondominant arm (Nguyen et al. 2003, Saad \& Vesely 2004, Sousa 2009, Sousa et al. 2014).

The ability to create an AVF depends on the existence of an arterial and venous network in good condition, namely the size and elasticity of the vessels. However, many patients during the evolutionary process of the disease are subject to numerous injuries in their arms. Frequent venipunctures and indiscriminate use of peripheral venous catheterisations can damage the network, compromising the construction and/or operation of the AVF (Hoggard et al. 2008). Peripheral catheterisations are one of the most common injuries, being associated with more than half of thrombosis of the vessels, which can reach $57 \%$ at the level of the cephalic vein, $14 \%$ in the basilic and $10 \%$ in the brachial (Allen et al. 2000). Thus, it is essential to teach the person to develop selfcare behaviours for the preservation of the vascular network, regardless of the selected modality of dialysis.

Nurses have a key role in the process of training self-care behaviours by providing information to the person, to encourage the use of their potential to acquire skills to identify, prevent and/or detect situations that could compromise the vascular network (Sousa 2012).

The construction of a scale to assess the self-care behaviours before construction of the AVF becomes relevant, it can be used to assess what type of intervention better allows the promotion of self-care. This article aims to describe the process of building a rating Scale of self-care behaviours anticipatory to creation of arteriovenous fistula (ASBAC-AVF) and its validation in patients with ESRD.

\section{Methods}

This is a cross-sectional study in which the development, construction and validation process followed the orientations of Streiner and Norman (2008). The study was conducted in two stages (Fig. 1) during 2012-2014 with the aim of constructing a scale that allowed the evaluation of self-care behaviours by patients with chronic renal disease to preserve the vascular network. The first stage corresponds to the scale construction process, while the second corresponds to the evaluation of the psychometric properties. 


\begin{tabular}{|c|c|}
\hline \multirow[t]{5}{*}{$\begin{array}{l}\text { First phase } \\
\text { Construction of ASBAC-AVF }\end{array}$} & $\begin{array}{l}\text { Theoretical background } \\
\text { - Review of literature } \\
\text { - Definition of items }\end{array}$ \\
\hline & $\downarrow$ \\
\hline & $\begin{array}{l}\text { Content validity } \\
\text { Expert panel } \\
\text { - } 1 \text { st painel } n=4 \text {, nephrology } \\
\text { nurses } \\
\text { - } 2 \text { nd panel } n=8 \text {, nephrology } \\
\text { nurses }(n=5) \text { and } \\
\text { nephrologists }(n=3)\end{array}$ \\
\hline & $\downarrow$ \\
\hline & Pretest, $n=14$ \\
\hline \multirow{4}{*}{$\begin{array}{l}\text { Second phase } \\
\text { Test the reliability and } \\
\text { validation of ASBAC-AVF }\end{array}$} & $\downarrow$ \\
\hline & $\begin{array}{l}\text { Test } \\
n=76 \text { end stage renal disease } \\
\text { - Sample analysis } \\
\text { - Reliability of internal } \\
\text { consistency: Cronbach's alpha } \\
\text { and item analysis }\end{array}$ \\
\hline & $\downarrow$ \\
\hline & $\begin{array}{l}\text { Construct validity } \\
\text { - Principal component analysis, } \\
\text { varimax rotation }\end{array}$ \\
\hline
\end{tabular}

Figure 1 Development process of the scale of assessment of selfcare behaviours anticipatory creation of arteriovenous fistula (ASBAC-AVF).

\section{Construction process}

Self-care behaviours were defined as all behaviours performed by the person intentionally to maintain the health or well-being (Orem 2001) directed for preserving the vascular network. We considered each behaviour of self-care as an item. The construction of the instrument began with the compilation of a set of self-care behaviours to include in the scale, based on clinical experience and literature review conducted by the researcher in the area of vascular access (Sousa et al. 2014). We had as aim building a simple scale without redundancy, allowing good acceptance/understanding by patients.

\section{Content validity}

Content validity was ensured by two panels of experts. The first panel consisted of nephrology nurses $(n=4)$, experienced in the evaluation of vascular access. The second panel was composed by nephrology nurses $(n=5)$ and nephrologists $(n=3)$, which integrate the consultation team of vascular access, with knowledge of the content for the conceptual structure. In each panel, the experts were asked to provide feedback about: clarity/conciseness; the similarity with other items; and relevance to the construct of each item. For clarity/conciseness, we sought to know if the item was understandable, perceivable, using simple and unequivocal terms and without possibility of other interpretations. For similarity with other items, we intended to find out if the item was not confusing and if it did not give the idea of repetition. For relevance to the construct, we intended to know the importance of the item to assess the self-care behaviour. The experts reviewed the items held against the above-mentioned criteria using the scale of agreement: $-1=$ strongly disagree, $0=$ neither disagree/neither agree, $1=$ agree. If the score was -1 or 0 , the experts were asked to suggest changes that seemed more relevant or to rewrite the item.

This process resulted in a version of six items that were arranged in a Likert-type scale of five points, ranging from 1 "never develop this self-care" to 5 "always develop this self-care".

One pretest was performed with the version of six items, which contained three reverse-scored items, which was applied to a sample of 14 renal patients with ESRD (ASBAC-AVF-6). The opinion of patients, the re-analysis of the content of the items made by the experts and internal consistency analysis led to the elimination of two items, originating a version of four items.

\section{Final version}

The re-analysis of experts and psychometric analysis showed a version of four items, which was designated as ASBAC-AVF-4. ASBAC-AVF has the minimum value of four points and the maximum value of 20 points (Fig. 2), the higher the score the better the self-care behaviour of the person to preserve the vascular network.

\section{Sample}

This study involved 90 patients who had ESRD and were followed in the outpatient nephrology from a Hospital in Northern Portugal. The study was conducted in two samples, the first $(n=14)$ and second sample $(n=76)$, whose sociodemographic characteristics are presented in Table 1. Inclusion criteria for the sample were as follows: patients older than 18 years; ESRD in stage 4/5; without vascular

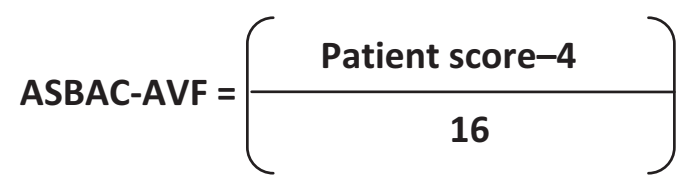

$\mathbf{X} 100$

Figure 2 Formula for calculating the scale of assessment of selfcare behaviours anticipatory creation of arteriovenous fistula (ASBAC-AVF). 


\begin{tabular}{|c|c|c|c|c|}
\hline & \multicolumn{2}{|l|}{ First sample $(n=14)$} & \multicolumn{2}{|c|}{$\begin{array}{l}\text { Second } \\
(n=76)\end{array}$} \\
\hline & $n$ & $\%$ & $n$ & $\%$ \\
\hline \multicolumn{5}{|l|}{ Gender } \\
\hline Male & 9 & $64 \cdot 29$ & 52 & 68.42 \\
\hline Female & 5 & $35 \cdot 71$ & 24 & 31.58 \\
\hline \multicolumn{5}{|l|}{ Scholarity } \\
\hline 4 years & 7 & $50 \cdot 00$ & 47 & $61 \cdot 84$ \\
\hline 6 years & 3 & 21.43 & 9 & $11 \cdot 84$ \\
\hline 9 years & 2 & $14 \cdot 29$ & 6 & $7 \cdot 89$ \\
\hline $11-12$ years & 1 & $7 \cdot 14$ & 8 & $10 \cdot 54$ \\
\hline Superior & 1 & $7 \cdot 14$ & 6 & $7 \cdot 89$ \\
\hline Age & \multicolumn{2}{|l|}{$\begin{array}{l}\text { Minimum: } 34 \text {; } \\
\text { Maximum: } 80 \\
\text { Mean: } 63 \cdot 43 \text {; SD:12.28 }\end{array}$} & \multicolumn{2}{|c|}{$\begin{array}{l}\text { Minimum: } 19 \text {; } \\
\text { Maximum: } 81 \\
\text { Mean: } 61 \cdot 61 ; \\
\text { SD: } 13.77\end{array}$} \\
\hline $\begin{array}{l}\text { Six-item cognitive } \\
\text { impairment test }\end{array}$ & \multicolumn{2}{|l|}{ Mean: $2.57 ;$ SD:1.69 } & \multicolumn{2}{|c|}{$\begin{array}{l}\text { Mean: } 2 \cdot 95 \text {; } \\
\text { SD: } 2 \cdot 03\end{array}$} \\
\hline
\end{tabular}

Table 1 Sociodemographic characteristics of participants who constitute the two samples $(n=14$ and $n=76)$ access and with no cognitive impairment. We used the sixitem cognitive impairment test to evaluate the cognitive status of each patient, adapted and validated for Portugal by Paiva (2013).

Participants were invited to participate in the study while waiting for the creation of the AVF. This is a convenience sample, sequential and nonprobabilistic.

\section{Procedures}

The study was approved by the ethics committee of the research unit in health sciences: Opinion 78-03/2012. Patients completed a questionnaire after signing informed consent. For patients who had no limitations in interpreting, the questionnaire was self-completed. Those who showed some limitation had assistance by the researcher.

\section{Statistical analysis}

The analysis was performed using the Statistical Package for Social Sciences Software (version 21.0; SPSS Inc., Chicago, IL, USA). In the construct validity, we opted to do the analysis of the main components to confirm what had conceptually emerged from the review of literature. We used the Cronbach's alpha, the Kaiser-Meyer-Olkin (KMO) and scree plot and the principal component analysis with varimax rotation, suppressing the factorial loads lower than $0 \cdot 30$.

\section{Results}

The literature review enabled to build six items that should integrate ASBAC-AVF. The first analysis of content held by experts originated that the following three items were rewritten: number 1 "I allow stings of veins in fistula arm", which became "I allow stings in the veins of the arm where it will be performed the fistula"; number 5 "I allow placing needles in fistula arm", which became "I allow placing needles in the arm where will be performed fistula" and number 6 "I allow blood pressure to be evaluated in fistula arm", which became "I allow the blood pressure to be measured in the arm where it will be performed the fistula". Any more items were eliminated or included. Re-analysis by the experts resulted in $100 \%$ consensus, being designated ASBAC-AVF-6.

\section{Analysis of internal consistency}

The ASBAC-AVF-6 was administered to an initial sample of 14 patients and was then subjected to an initial analysis of internal consistency revealing values of Cronbach's $\alpha$ coefficient ranging between 0.363-0.679 (Table 2). The data on the correlation of the item with the total score of the scale revealed one problematic item (number 3) were eliminated, because presented a negative correlation. The second analysis of content of the scale was re-analysed by experts removing item number 2, because it was not relevant for the present instrument. A second analysis of internal consistency of the four items, which revealed Cronbach's $\alpha$ values ranging between $0 \cdot 608-0.798$, which allow considering them good, was accomplished.

The ASBAC-AVF-4 was administered to the second sample of 76 patients, the internal consistency analysis show that Cronbach's $\alpha$ varies between $0 \cdot 711-0 \cdot 879$. The Cronbach's $\alpha$ the ASBAC-AVF-4 is 0.831 (Table 3 ). 


\section{Analysis of construct}

The principal component analysis indicated that the matrix allowed factorial analysis, with only one factor in its structure $(\mathrm{KMO}=0.759$, Bartlett's sphericity test approximate Chi-square 142,201, $p<0.000$ ), depending on the own

Table 2 Correlations of items with the total score of scale of assessment of self-care behaviours anticipatory creation of arteriovenous fistula (ASBAC-AVF-6) $(n=14)$

\begin{tabular}{lcl}
\hline $\begin{array}{l}\text { Items of ASBAC-AVF } \\
\begin{array}{l}\text { 1 - I allow stings in the } \\
\text { veins of the arm where }\end{array}\end{array}$ & $\begin{array}{c}\text { Corrected item- } \\
\text { total correlation }\end{array}$ & $\begin{array}{l}\text { Cronbach's } \alpha \text { if } \\
\text { item deleted }\end{array}$ \\
$\begin{array}{l}\text { it will be performed the } \\
\text { fistula }\end{array}$ & 0.376 & 0.551 \\
$\begin{array}{l}\text { - I put hydrant skin } \\
\text { cream in my arms }\end{array}$ & 0.201 & 0.609 \\
$\begin{array}{l}3 \text { - I allow blood samples } \\
\text { to be made on the back } \\
\text { of the hand }\end{array}$ & -0.055 & 0.679 \\
$\begin{array}{l}\text { - Protect arms from bumps } \\
\text { and knocks }\end{array}$ & 0.297 & 0.580 \\
$\begin{array}{l}5 \text { - I allow placing needles in } \\
\text { the arm where will be } \\
\text { performed fistula }\end{array}$ & 0.736 & 0.363 \\
$\begin{array}{l}\text { - I allow that the blood } \\
\text { pressure is measured in the } \\
\text { arm where it will be } \\
\text { performed the fistula }\end{array}$ & 0.491 & 0.678 \\
\hline
\end{tabular}

values and their distribution in the scree plot (Fig. 3). A principal component analysis confirmed the univariate structure of the scale with four items.

\section{Discussion}

The results show that the ASBAC-AVF-4 is a tool to assess the quality of self-care behaviours in the preservation of the vascular network by patients, before the creation of AVF.

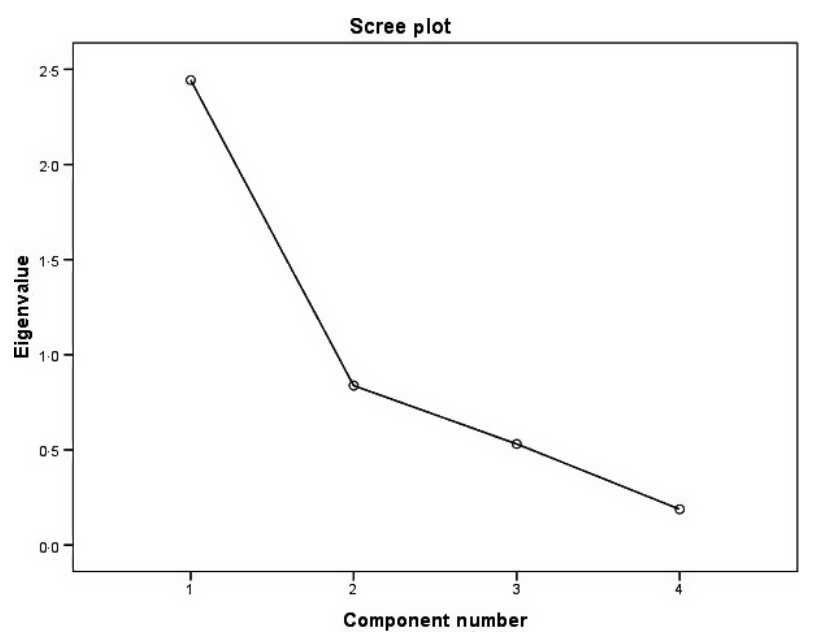

Figure 3 Cattel Scree test of the component factors of the scale of assessment of self-care behaviours anticipatory creation of arteriovenous fistula (ASBAC-AVF)-4.

Table 3 One-factor structure and internal consistency coefficients (Cronbach's $\alpha$ ) of the scale of assessment of self-care behaviours anticipatory creation of arteriovenous fistula (ASBAC-AVF) $(n=76)$

\begin{tabular}{|c|c|c|c|c|c|c|}
\hline Items & Limits & Mean & $\begin{array}{l}\text { Standard } \\
\text { deviation }\end{array}$ & $\begin{array}{l}\text { Factorial } \\
\text { load }\end{array}$ & $\begin{array}{l}\text { Correlation } \\
\text { item-total } \\
\text { correlation }\end{array}$ & $\begin{array}{l}\text { Cronbach's } \alpha \text { if } \\
\text { item deleted }\end{array}$ \\
\hline $\begin{array}{l}\text { 1. I allow stings in the } \\
\text { veins of the arm where } \\
\text { it will be performed the } \\
\text { fistula* }\end{array}$ & $1-5$ & $4 \cdot 11$ & 1.502 & $0 \cdot 871$ & 0.727 & 0.755 \\
\hline $\begin{array}{l}\text { 2. Protect arms from } \\
\text { bumps and knocks }\end{array}$ & $1-5$ & $4 \cdot 13$ & $1 \cdot 204$ & 0.596 & 0.417 & 0.879 \\
\hline $\begin{array}{l}\text { 3. I allow placing needles } \\
\text { in the arm where will be } \\
\text { performed fistula* }\end{array}$ & $1-5$ & $4 \cdot 16$ & $1 \cdot 367$ & 0.921 & 0.822 & 0.711 \\
\hline $\begin{array}{l}\text { 4. I allow that the blood } \\
\text { pressure is measured in the } \\
\text { arm where it will be } \\
\text { performed the fistula* }\end{array}$ & $1-5$ & $4 \cdot 04$ & 1.418 & $0 \cdot 850$ & 0.697 & 0.769 \\
\hline KMO & & & & & & 0.759 \\
\hline Bartlett's sphericity test & & & & & & $142,201, p<0 \cdot 000$ \\
\hline Cronbach's $\alpha$ & & & & & & $0 \cdot 831$ \\
\hline
\end{tabular}

*Reversed items. 
In the construction process of the scale (ASBAC-AVF-6), the literature highlighted the need for patient to be taught to preserve the vascular network. The self-care behaviours should be performed by patients, to not damage the vascular network. In the psychometric process, one item ("I allow blood samples to be made on the back of the hand") was eliminated because it had a negative correlation with the factor, which means it had an opposite behaviour to that of other items. Patients do not do this behaviour, but they do the other self-care behaviours. The item "I put hydrant skin cream in my arms" was eliminated because of the limited relevance of the item considered by the experts.

The ASBAC-AVF shows an internal consistency of 0.831, wherein Cronbach's $\alpha$ value varies between 0.711 0.879 . If the item number 2 "Protect arms from bumps and knocks" was eliminated the Cronbach's $\alpha$ would be 0.879 . But, because of the importance of the content assessed by item, we decided to keep it in the final version. A factorial analysis revealed the existence of a single factor, confirming what was mentioned in the literature review. This is a univariate scale. It is intended in future to apply ASBAC-AVF to a new and larger sample for the determination of construct validity, including convergent validity.

The ASBAC-AVF can be used in further research to evaluate the strategies used in patients empowerment to preserve the vascular network, can also be inserted into programmes of conservative treatment to assess the selfcare of patients with the vascular network.

\section{Conclusion}

The ASBAC-AVF revealed properties that enable its use to assess the self-care behaviours by patients in the preservation of the vascular network. This is a univariate scale, which showed very good internal consistency, with Cronbach's $\alpha$ value greater than 0.779 , which supports the reliability of the scale. This scale can identify the self-care behaviours most accomplished by patients with end-stage renal disease to preserve vascular network.

\section{Relevance to clinical practice}

The ASBAC-AVF can be used to assess future educational programmes for the development of self-care behaviours in the prevention of vascular network and to identify the selfcare behaviours most accomplished by patients with endstage renal disease to preserve the vascular network. This scale can identify not only the patients that are able to take care of their vascular network, but also the proportion of patients who are not able to do it, that need to be educated.

\section{Acknowledgements}

We thank at Centro Hospitalar Vila Nova de Gaia/Espinho, especially nephrology department and ambulatory surgery department.

\section{Contributions}

Study design: CNS, JLA, MHF, PT, VFD; Data collection and analysis: CNS, JLA, PT, VFD and Manuscript preparation: CNS, VFD.

\section{Conflict of interest}

The authors do not have interest conflict and did not have funding.

\section{References}

Allen AW, Megargell JL, Brown DB, Lynch FC, Singh H, Singh Y \& Waybill PN (2000) Venous thrombosis associated with the placement of peripherally inserted central catheters. Journal Vascular Interventional Radiology 11, 1309-1314.

Besarab A \& Brouwer D (2004) Improving arteriovenous fistula construction: fistula first initiative. Hemodialysis International 8, 199-206.

Dinwiddie LC (2003) Investing in the lifeline: the value of a vascular access coordinator. Nephrology News Issues 17, 49-53.
SEN Guidelines (2005) Guías de acceso vascular en hemodiálisis. Nefrologia 25(Suppl. 1), 3-97.

Hoggard J, Saad T, Schon D, Vesely TM \& Royer T (2008) Guidelines for venous access in patients with chronic kidney disease. A position statement from the American Society of Diagnostic and Interventional Nephrology Clinical Practice Committee and the Association for Vascular Access. Seminars Dialysis 21, 186-191.

Konner K, Nonnast-Daniel B \& Ritz E (2003) The arteriovenous fistula. Jour- nal American Society Nephrology 14, 1669-1680.

Nguyen VD, Grifith C \& Treat L (2003) A multidisciplinary team approach to increasing AV fistula creation: a community-based nephrology practice experience. Nephrology News Issues $17,54-56$.

NKF-K/DOQI (2006) Clinical practice guidelines for vascular access: update. American Journal Kidney Diseases 48 (Suppl. 1), S176-S276.

Orem D (2001) Nursing: Concepts of Practice. Mosby, St. Louis, MO. 
Paiva DS (2013) Cognition and aging: study of adaptation and validation of six item cognitive impairment test (6CIT). Master Degree Dissertation in Escola Superior de Enfermagem de Coimbra, Portugal.

Pile C (2004) Hemodialysis vascular access: how do practice patterns affect outcomes? Nephrology Nursing Journal 31, 305-308.

Pisoni RL, Young EW, Dykstra DM, Greenwood RN, Hecking E, Gillespie B, Wolfe RA, Goodkin DA \& Held PJ (2002) Vascular access use in Europe and the United States: results from the DOPPS. Kidney International 61, 305-316.

Saad TF \& Vesely TM (2004) Venous access for patients with chronic kidney disease. Journal Vascular Interventional Radiology 15, 1041-1045.

Schon D, Blume SW, Niebauer K, Hollenbeak CS \& de Lissovoy G (2007) Increasing the use of arteriovenous fistula in hemodialysis: economic benefits and economic barriers. Clinical Journal American Society Nephrology 2, 268-276.

Schoolwerth AC, Engelgau MM, Hostetter TH, Rufo KH, Chianchiano D, McClellan WM, Warnock DG \& Vinicor F (2006) Chronic kidney disease: a public health problem that needs a public health action plan. Preventing Chronic Disease 32(2), A57.

Sousa CN (2009) Care for Arteriovenous Fistula: of the theoretical presuppositions to contexts of practice. Master Degree Dissertation in Instituto Ciências Biomédicas Abel Salazar da Universidade do Porto, Portugal.

Sousa CN (2012) Caring for the person arteriovenous fistula: model for continuous improvement. Portuguese Journal Public Health 30, 11-17.

Sousa CN, Apóstolo JL, Figueiredo MH, Martins MM \& Dias VF (2014) Interventions to promote self-care of people with arteriovenous fistula.
Journal Clinical Nursing 23, $1796-$ 1802.

Streiner DL \& Norman GR (2008) Health Measurement Scales: A Practical Guide to the Development and Use, 4th edn. Oxford University Press, New York, NY.

Tordoir J, Canaud B, Haage P, Konner K, Basci A, Fouque D, Kooman J, MartinMalo A, Pedrini L, Pizzarelli F, Tattersall J, Vennegoor M, Wanner C, ter Wee P \& Vanholder R (2007) EBPG (European Best Practice Guidelines) on vascular access. Nephrology Dialysis Transplantation 22(Suppl. 2), ii88-ii117.

USRDS (2009) Costs of CKD. American Journal Kidney Disease 53(Suppl. 1), S81-S90.

Young EW, Dykstra DM, Goodkin DA, Mapes DL, Wolfe RA \& Held PJ (2002) Hemodialysis vascular access preferences and outcomes in the dialysis outcomes and practice patterns study (DOPPS). Kidney International 61, 2266-2271. 